\title{
Contraceptive situation and Influencing Factors in Guangdong Province: A comparative questionnaire study
}

\section{FAN JIANG}

Guangzhou Women and Children's Medical Center

\section{Yanxia Qu}

Guangzhou Women and Children's Medical Center

Peixuan Lin

Guangzhou Women and Children's Medical Center

Li Li

Guangzhou Women and Children's Medical Center

\section{Qingshan Xuan}

Guangzhou Women and Children's Medical Center

\section{Yaojuan He}

Guangzhou Women and Children's Medical Center

\section{Aihua Zhang}

Guangzhou Women and Children's Medical Center

Qingfeng Li ( $\square$ 8819130228@qq.com )

Guangzhou Women and Children's Medical Center

\section{Research}

Keywords: Contraception, Post-abortion care, Long acting reversible contraception, Induced abortion

Posted Date: February 23rd, 2021

DOl: https://doi.org/10.21203/rs.3.rs-220653/v1

License: (c) (i) This work is licensed under a Creative Commons Attribution 4.0 International License. Read Full License 


\section{Abstract}

\section{Background}

The aim of our study is to describe the status of induced abortion and contraceptive use in reproductive women and make clear the correlated factors in Guangdong province.

Method

A self-administered questionnaire survey was conducted separately in 1839 individuals aged 18-49 and 900 health care providers from Guangdong province. The content of questionnaire was based on status of induced abortion and contraceptive use for the former and problems concerning contraceptive services for the latter. Systematic random sampling was used and data were analyzed using SPSS 19.0. Descriptive statistics and binary logistic regression were used in this study.

Results

$30.61 \%$ of participants experienced the induced abortion. The rate of repeated abortion was $19.96 \%$ and it was $20.45 \%$ in persons under 20 years old. $18.23 \%$ of 1839 individuals chose LARC as the main contraceptive method. The females with college degree(Odds ratio, OR $=1.867 ; 95 \%$ confidence intervals $95 \% \mathrm{Cl}: 1.175-2.969)$, technologists $(\mathrm{OR}=2.291 ; 95 \% \mathrm{Cl}: 1.063-4.936)$ and the persons whose monthly income were of between $3000-5000 ¥(O R=1.920 ; 95 \% \mathrm{Cl}: 1.204-3.065)$ were more likely to use LARC. The younger females less than 30 years old and never using PAC services had lower odds of using LARC. The rate of post abortion care performance was merely $12.23 \%$. Age, monthly income, occupation, living conditions and obtaining free contraceptives in time were all strongerly influence factors for the use of post-abortion care $(P<0.01)$. The satisfaction rate of free contraceptive services was about $57.44 \%$. Variety uniformity, obtaining inconveniently and worrying about the quality were the main reasons. $66.22 \%$ of hospitals set up the department of family planning in our study. Highly work intensity $(54.67 \%)$ and less leadership (40.22\%) influenced health care providers to provide family planning services.

\section{Conclusion}

The abortion rate was high especially in young women. There were many problems affecting contraceptive services which damaged women'reproductive health. Increasing government investment for family planning services, strengthening the construction of the family planning department and performing post abortion care and long-acting reversible contraception by taking relevant steps would be useful measures for improving current contraceptive status.

\section{Plain English Summary}

The abortion rate of Guangdong province was in the forefront but the contraceptive prevalence rate was low in china. The detailed data in populations with different background were scared. LARCs and PAC services are useful to reduce the unintended pregnancy. Many factors influencing the performance of 
LARC and PAC should be done more research. The questionaire survey contains 50 questions including the basic demographic characteristics, the level of LARC utilization and the intention to use LARC, the situation of PAC performance and barriers to obtain free contraceptive services. In particular, the questionaire for health care providers was based on health care providers' attitudes to LARC and problems in supplying contraceptive services.

We found that $30.61 \%$ of women in reproductive age experienced the induced abortion. The rate of repeated induced abortion was high in unmarried yonger women. Older women(>41years), having one child at least, obtaining PAC and free contraceptives services in time tended to select LARC. The rate for the use of PAC was low in our survey. Age, job types, living condition, monthly income and obtaining free contraceptives conveniently were the main factors. Free contraceptives were also helpful to promote LARC use while variety uniformity and worrying about the quality were barriers. Workplaces providing PAC services were correlated with correct attitude of regarding IUDs use in health care providers. Improving leadership management and setting up the department of family planning in hospitals may be applicable measures.

\section{Background}

Many research indicated that the absolute number of abortions world-wide increased $56 \cdot 3$ million per year in recent years and $27 \%$ of abortions happened in unmarried young women. In the developed world, the annual abortion rate declined significantly but it still maintained in 37 abortions per 1000 women in the developing world[1]. The 2018 China Health Statistical Yearbook showed that the number of induced abortions attained 9.74 million in 2018 in china [2]. 55.9\% of induced abortion women experience multiple abortion, which was $43.1 \%$ in the United States $[3,4]$. More and more young people had more than one induced abortion experiences. High risk induced abortion presented an up-trend. Induced abortion seriously threatened the women'health. Women with induced abortion may suffer complications and adverse pregnancy outcome in pregnancies including low birthweight, preterm birth and others[5]. Some researches showed that the induced abortion increased risk of mental disorders especially in unmarried women[6]. Long-acting reversible contraceptives (LARCs) have been proved as the most cost-effective methods to prevent unintended pregnancies especially reduce the rate of repeat abortions during the post abortion period[7]. It has been recommended by the American College of Obstetricians[8]. With the loosened birth policy, contraceptive use condition has changed since 2016. Although the total contraceptive prevalence rates remain around $80 \%$ which is the highest in the world, more and more women choose the short-term and self-controlled contraceptive methods. IUD usage decreased from $20.98 \%$ in 2014 to $10.73 \%$ in 2018. Post-abortion care (PAC) counseling was first proposed in 1991 and many reports showed that it could also induced abortions $[9,10]$. Although PAC had been provided in 799 hospitals since 2010 , the promotion of PAC in child-bearing age people was not enough (http://www.yiaijijin.org.cn/html/xinwenzixun/1609.html). Limited understanding of LARCs and lack of high-quality post-abortion care (PAC) services are the major reasons for the largest number of induced abortion in china. 
The contraceptive prevalence rate in Guangdong province was only $71.6 \%$ ranking the 27 th while the rate of induced abortion was in the second place around the country. The number of internal migrants living was largest in china. Most of the migrant women were in the child-bearing age and lacked contraceptive knowledge and correct attitude. It was not easy for them to obtain the free family planning services. Free PAC services have been provided in 104 hospitals but the understanding of PAC services is not enough depth and thorough in such people of childbearing age. The objective of our study is to evaluate the present situation of contraception and abortion including the knowledge and the offering situation of LARCs and PAC services, the factors that influenced people to obtain free contraceptive services.

\section{Materials And Methods}

Study design and setting

We designed the questionnaire using an APP to collect data. Participants with 18-49-year-old who had sexual life in Guangdong province were recruited in our study. This study observed the voluntary participation principle and was approved by Guangzhou Women \& Children Medical Center's ethics committee. The questionnaire included questions on: (1)basic demographics; (2)occupation; (3)marriage and fertility status; (4)contraceptive use; (5)history of abortion; (6)contraceptive status; (7) difficulties in receiving free contraceptive and PAC services; and (8) knowledge and acceptance of LARCs and PAC. We also recruited 900 health care providers to reveal problems encountered with in providing the contraceptive services and attitudes towards LARCs and PAC use in abortion or postpartum women. The questions were close-ended. In order to ensure all participants to easily understand the questionnaire, we used simple language and conducted a pre-survey. We excluded cases with incomplete data and reviewed the questionnaire by experienced obstetricians. SPSS 19.0 was utilized to analyze the data. A chi-Square test and logistic regression analysis were performed to analyze factors influencing the status of induced abortion, the choice of contraceptive methods and knowledge of LARCs and PAC. Chi square analysis, descriptive statistics and binary logistic regression were employed in our study. We also chose Odds ratios (ORs) and 95\% confidence intervals (Cls) to calculate. A p-value of less than 0.05 was regarded as statistically significant.

\section{Results}

\section{Socio-demographic characteristics of all participants}

93.26\% of 1839 participants were of Han ancestry, the average age of which were $33.5 \pm 8.17$ years. Among them, $69.01 \%$ had a college education and approximately half $(52.04 \%)$ had individual income per month over 5000 RMB. $83.14 \%$ of those persons were married. $78.47 \%$ had one child at least. $93.2 \%$ of those 1839 persons were employed. Table 1 showed all the demographic information for 1839 common participants. All those 900 health care providers came from hospitals(80.33\%) or family planning organizations(19.67\%). 93.88\% of them were obstetrics and gynecology physicians and others were 
family planning practitioners. In those obstetrics and gynecology physicians, $21.02 \%$ served in the department of family planning in hospitals. 
Table 1

Socio-demographic characteristics of participants $(n=1839)$

\begin{tabular}{|c|c|c|c|}
\hline \multicolumn{2}{|c|}{ Socio-demographic characteristics } & \multirow{2}{*}{$\begin{array}{l}\text { cases } \\
666\end{array}$} & \multirow{2}{*}{$\begin{array}{l}\text { Frequency (\%) } \\
36.22\end{array}$} \\
\hline Age(years) ${ }^{a}$ & $\leq 30$ & & \\
\hline & $31-40$ & 758 & 41.22 \\
\hline & $\geq 41$ & 415 & 22.57 \\
\hline \multirow[t]{2}{*}{ Nationality } & Han nationality & 1715 & 93.26 \\
\hline & minority nationality & 124 & 6.74 \\
\hline \multirow[t]{4}{*}{ Level of education } & Junior high school or below & 263 & 14.30 \\
\hline & Middle special / senior high school & 307 & 16.69 \\
\hline & Junior college & 1178 & 64.06 \\
\hline & Master degree or above & 91 & 4.95 \\
\hline \multirow[t]{2}{*}{ Marital status } & Unmarried & 256 & 13.92 \\
\hline & Married & 1583 & 86.08 \\
\hline \multirow[t]{3}{*}{ Number of children } & 0 & 396 & 21.53 \\
\hline & 1 & 708 & 38.50 \\
\hline & $\geq 2$ & 735 & 39.97 \\
\hline \multirow[t]{5}{*}{ Occupation } & Public employees & 389 & 21.15 \\
\hline & Professional and technical personnel & 716 & 38.93 \\
\hline & Self-employed & 112 & 6.09 \\
\hline & Farming & 497 & 27.03 \\
\hline & Unemployed & 125 & 6.80 \\
\hline \multirow[t]{2}{*}{ Account } & Country registered residence & 890 & 48.40 \\
\hline & City registered residence & 949 & 51.60 \\
\hline \multirow[t]{4}{*}{ Monthly income } & $<3000 ¥$ & 291 & 15.82 \\
\hline & $3000-5000 ¥$ & 591 & 32.14 \\
\hline & $5000-10000 ¥$ & 509 & 27.68 \\
\hline & $>100000 ¥$ & 448 & 24.36 \\
\hline \multirow[t]{2}{*}{ Living condition } & Rural area & 552 & 36.22 \\
\hline & Urban & 1085 & 41.22 \\
\hline
\end{tabular}




\begin{tabular}{|llll|}
\hline Socio-demographic characteristics & cases & Frequency (\%) \\
\hline \multirow{3}{*}{ Number of boys } & Suburb & 202 & 22.57 \\
& 0 & 825 & 14.30 \\
& 1 & 791 & 16.69 \\
& $\geq 2$ & 223 & 64.06 \\
\hline
\end{tabular}

\section{Status of abortion and Conception Control}

$30.61 \%(563 / 1839)$ of participants had the history of induced abortion, and 19.96\% (367/930) experienced repeated abortion. $28.90 \%$ of 256 unmarried women had at least one abortion. Only $45.02 \%$ of 1839 participants insisted on adopting contraceptive methods every time during sex. $25.93 \%$ (477/1839) chose a LARC as the main contraceptive method.

\section{Performance of PAC and in our study}

$12.23 \%$ of participants applied PAC services. The women with age less than 20 -years old or receiving only elementary school education or even lower knowing nothing about PAC services. Comparing to persons beyond 41 years old, the women with age between 20-40 years olds seldom used PAC services(OR:0.301 95\%Cl: $0.167-0.541$ for the group of $20-30$ years old and OR:0.474, $95 \% \mathrm{Cl}: 0.321-0.701$ for the group of 30-40 years old respectively). Participants who lived in urban had a higher prevalence of using PAC services(OR:2.798, 95\%Cl: 1.419-5.496). Except that, women with technical jobs just like lawyers, teachers or medical staffs more frequently used PAC services(OR:6.971, 95\%Cl: $1.580-30.76)$. We pointed out the person with monthly income lower than $10000(p<0.01)$ and the person obtaining free contraceptives inconveniently $(p=0.000)$ was main influencing factors for the acceptability of PAC services(Table 2). In our investment for 900 health care providers, $66.11 \%$ of their work units provided PAC services. PAC services were carried out mainly in 3-A-grade General Hospitals and maternal and child health institutions The application of PAC services was only $12.4 \%$ in primary hospitals. There was significant difference in rates of supplying PAC services between their workplaces with and without the department of family planning. 
Table 2

Main factors associated with PAC use among participants: logistic regression.

\begin{tabular}{|c|c|c|c|}
\hline Variable & & Odds ratio (95 Cl) & $\begin{array}{l}P- \\
\text { Value }\end{array}$ \\
\hline \multirow[t]{3}{*}{ Age } & $21-30$ & $\begin{array}{l}0.301(0.167- \\
0.541)\end{array}$ & $0.000 *$ \\
\hline & $31-40$ & $\begin{array}{l}0.474(0.321- \\
0.701)\end{array}$ & $0.000 *$ \\
\hline & $\geq 41$ & 1 & \\
\hline \multirow[t]{5}{*}{ Occupation } & Public employees & $\begin{array}{l}3.572(0.791- \\
16.121)\end{array}$ & 0.098 \\
\hline & $\begin{array}{l}\text { Professional and technical } \\
\text { personnel }\end{array}$ & $\begin{array}{l}6.971(1.580- \\
30.760)\end{array}$ & $0.010 *$ \\
\hline & Self-employed & $\begin{array}{l}2.963(0.552- \\
15.889)\end{array}$ & 0.205 \\
\hline & Farming & $\begin{array}{l}5.942(0.731- \\
16.246)\end{array}$ & 0.095 \\
\hline & Unemployed & 1 & \\
\hline \multirow[t]{4}{*}{ Monthly income } & $<3000 ¥$ & $0.772(0.378-1.827$ & 0.517 \\
\hline & $3000-5000 ¥$ & $\begin{array}{l}0.452(0.277- \\
0.739)\end{array}$ & $0.002 *$ \\
\hline & $5000-10000 ¥$ & $\begin{array}{l}0.612(0.404- \\
0.928)\end{array}$ & $0.021^{\star}$ \\
\hline & $>100000 ¥$ & 1 & \\
\hline \multirow[t]{3}{*}{ Living condition } & Rural area & $\begin{array}{l}1.315(0.564- \\
3.064)\end{array}$ & 0.553 \\
\hline & Urban & $\begin{array}{l}2.798(1.419- \\
5.496)\end{array}$ & $0.003^{*}$ \\
\hline & Suburb & 1 & \\
\hline \multirow[t]{2}{*}{$\begin{array}{l}\text { Obtain free contraceptives in } \\
\text { time }\end{array}$} & Not in time & $\begin{array}{l}0.269(0.172- \\
0.422)\end{array}$ & 0.000 \\
\hline & In time & 1 & \\
\hline
\end{tabular}

Factors associated with applications of free Contraceptives

In our study, 51.22\% (942/1839) of people did not obtain contraceptives free of charge from the government. Worrying about the quality of contraceptives, being unsatisfied with models and types and 
feeling embarrassed were main reasons for them to refuse free contraceptives. All those influence factors were described in Fig. 1. Family planning departments, self-service terminal for free contraceptives and department of gynecology in public hospitals are main sources of which people at reproductive age to obtain free contraceptives(88.4\%). The satisfaction with those approachs was only $57.44 \%(874 / 1839)$. Youger women(20-40 years old) had a lower incidence of using free contraceptives comparing to women being over 40 year-old. The participants'monthly income lower than 3000 or between $3000-5000$ had higher odds of using free contraceptives(OR: 2.119, 95\%Cl:1.125-3.991 and OR: 2.014, 95\%Cl:1.2603.221 respectively) The higher income people, the population living in urban and suburb, and the persons being self-employed or without working did not intend to obtain free contraceptives $(p<0.05)$ (Table 3$)$. We also analyzed the influence factors for betimes of obtaining free contraceptives. The major factors were also associated with intention to use free contraceptives. Another factor that the women had more than one boy was also strongly associated with timeliness(OR:2.066, 95\%Cl:1.265-3.374) (Table 4). 
Table 3

The strong influence factors associated with intention to use free contraceptives

\begin{tabular}{|c|c|c|c|}
\hline Variable & & Odds ratio (95 Cl) & $\begin{array}{l}\text { P- } \\
\text { Value }\end{array}$ \\
\hline \multirow[t]{3}{*}{ Age(years)a } & $\leq 30$ & $\begin{array}{l}0.335(0.201- \\
0.560)\end{array}$ & $0.000 *$ \\
\hline & $31-40$ & $\begin{array}{l}0.011(0.423- \\
0.869)\end{array}$ & $0.011 *$ \\
\hline & $\geq 41$ & 1 & \\
\hline \multirow[t]{5}{*}{ Occupation } & Public employees & $\begin{array}{l}2.441(1.036- \\
5.754)\end{array}$ & $0.041^{*}$ \\
\hline & $\begin{array}{l}\text { Professional and technical } \\
\text { personnel }\end{array}$ & $\begin{array}{l}2.336(1.001- \\
5.450)\end{array}$ & $0.050 *$ \\
\hline & Self-employed & $\begin{array}{l}0.779(0.234- \\
2.590)\end{array}$ & 0.464 \\
\hline & Farming & $\begin{array}{l}2.738(0.819- \\
9.150)\end{array}$ & $0.102^{*}$ \\
\hline & Unemployed & 1 & \\
\hline \multirow[t]{4}{*}{ Monthly income } & $<3000 ¥$ & $\begin{array}{l}2.119(1.125- \\
3.991)\end{array}$ & 0.02 \\
\hline & $3000-5000 ¥$ & $\begin{array}{l}2.014(1.260- \\
3.221)\end{array}$ & 0.003 \\
\hline & $5000-10000 ¥$ & $\begin{array}{l}1.208(0.770- \\
1.895)\end{array}$ & 0.412 \\
\hline & $>10000 ¥$ & 1 & \\
\hline \multirow[t]{3}{*}{ Living condition } & Rural area & $\begin{array}{l}2.059(1.139- \\
3.722)\end{array}$ & $0.017 *$ \\
\hline & Urban & $\begin{array}{l}0.843(0.506- \\
1.403)\end{array}$ & 0.511 \\
\hline & Suburb & 1 & \\
\hline \multirow[t]{2}{*}{$\begin{array}{l}\text { Obtain free contraceptives in } \\
\text { time }\end{array}$} & Not in time & $\begin{array}{l}0.083(0.043- \\
0.160)\end{array}$ & $0.000 *$ \\
\hline & In time & & \\
\hline
\end{tabular}


Table 4

The strong influence factors associated with the timeliness of free contraceptives use

\begin{tabular}{|c|c|c|c|}
\hline \multicolumn{2}{|l|}{ Variable } & \multirow{2}{*}{$\begin{array}{l}\text { Odds ratio }(95 \mathrm{Cl}) \\
0.389(0.261-0.580)\end{array}$} & \multirow{2}{*}{$\begin{array}{l}\text { P-Value } \\
0.000 *\end{array}$} \\
\hline Age(years)a & $\leq 30$ & & \\
\hline & $31-40$ & $0.436(0.310-0.615)$ & $0.000 *$ \\
\hline & $\geq 41$ & 1 & \\
\hline \multirow[t]{4}{*}{ Level of education } & Junior high school or below & $0.375(0.112-1.252)$ & 0.111 \\
\hline & Middle special / senior high school & $0.340(0.485-1.029)$ & $0.000 *$ \\
\hline & Junior college & $0.706(0.485-1.029)$ & 0.070 \\
\hline & Master degree or above & 1 & \\
\hline \multirow[t]{5}{*}{ Occupation } & Public employees & $1.477(1.096-2.609)$ & $0.042^{\star}$ \\
\hline & Professional and technical personnel & $1.775(1.096-3.061)$ & $0.02^{\star}$ \\
\hline & Self-employed & $0.737(0.412-1.318)$ & 0.303 \\
\hline & Farming & $4.601(0.956-22.151)$ & 0.057 \\
\hline & Unemployed & 1 & \\
\hline \multirow[t]{4}{*}{ Monthly income } & $<3000 ¥$ & $1.780(1.085-2.920)$ & $0.022^{\star}$ \\
\hline & $3000-5000 ¥$ & $1.974(1.388-2.809)$ & $0.000 *$ \\
\hline & $5000-10000 ¥$ & $1.680(1.222-2.309)$ & $0.001^{*}$ \\
\hline & $>100000 ¥$ & 1 & \\
\hline \multirow[t]{3}{*}{ Living condition } & Rural area & $1.155(0.731-1.871)$ & 0.559 \\
\hline & Urban & $0.536(0.354-0.811)$ & $0.003^{*}$ \\
\hline & Suburb & 1 & \\
\hline \multirow[t]{3}{*}{ Number of boys } & $\geq 2$ & $2.066(1.265-3.374)$ & $0.004^{*}$ \\
\hline & 1 & $1.354(0.999-1.835)$ & 0.051 \\
\hline & 0 & 1 & \\
\hline
\end{tabular}

Our survey showed that the contraceptives free of charge were provided in $87.22 \%$ of the 900 health care providers' work units. Obtaining from self-service terminal for free contraceptives(35.84\%) and having prescriptions of free contraceptives after counselling $(21.74 \%)$ were main approaches. The staff faced many difficulties in promoting contraceptive service provision, which were showed in Fig. 2. 


\section{Knowledge and performance of LARC and in our study}

In this study, only $46.80 \%$ of 1839 people know exactly about types of LARC. Few ( $9.74 \%$ had used IUDs, $1.53 \%$ had used implants and $6.96 \%$ had used vasoligation or female ligation) used LARC. $27.80 \%$ participant took regard condom as LARC and $50.49 \%$ of them took the condom as the main contraceptive method. $29.8 \%$ of the women had the intention to use IUDs or implants during the post abortion period. By using binary logistic regression, the following factors for LARC use were identified as risk factors for age, job, educational level, monthly income, the use of PAC services. (Table 5). We also used binary logistic regression logistic regression to analyze variables that had the significant correlation with a woman's intention to use a LARC after abortion or after childbirth. The result showed that the women who had less than one boy, used PAC services, obtained free contraceptives and were between 30-40 years old were more likely to use a LARC(Table 6).

\section{Table 5}

The main factors associated with LARCs use in our study

\begin{tabular}{|c|c|c|c|}
\hline \multicolumn{2}{|l|}{ Variable } & \multirow{2}{*}{$\begin{array}{l}\text { Odds ratio (95 Cl) } \\
0.483(0.284-0.822)\end{array}$} & \multirow{2}{*}{$\begin{array}{l}\text { P-Value } \\
0.007^{\star}\end{array}$} \\
\hline Age(years)a & $\leq 30$ & & \\
\hline & $31-40$ & $0.724(0.494-1.061)$ & $0.097 *$ \\
\hline & $\geq 41$ & 1 & \\
\hline \multirow[t]{4}{*}{ Level of education } & Junior high school or below & $2.766(0.604-12.688)$ & 0.190 \\
\hline & Middle special / senior high school & $1.742(0.870-3.491)$ & $0.117 *$ \\
\hline & College & $1.867(1.175-2.969)$ & $0.008^{*}$ \\
\hline & Master degree or above & 1 & \\
\hline \multirow[t]{5}{*}{ Occupation } & Public employees & $0.748(0.380-1.880)$ & 0.681 \\
\hline & Technologists & $2.291(1.063-4.936)$ & $0.034^{\star}$ \\
\hline & Self-employed & $1.017(0.413-2.552)$ & 0.955 \\
\hline & Farming & $0.614-7.715$ & 0.235 \\
\hline & Unemployed & 1 & \\
\hline \multirow[t]{4}{*}{ Monthly income } & $<3000 ¥$ & $1.740(0.887-3.412)$ & 0.107 \\
\hline & $3000-5000 ¥$ & $1.920(1.204-3.065)$ & $0.006^{*}$ \\
\hline & $5000-10000 ¥$ & $1.043(0.666-1.634)$ & 0.853 \\
\hline & $>100000 ¥$ & 1 & \\
\hline \multirow[t]{2}{*}{ Use of PAC services } & No & $0.413-0.941$ & $0.025^{\star}$ \\
\hline & Yes & 1 & \\
\hline
\end{tabular}


Table 6

Associations between factors and an intention to use LARCs among women with unintended pregnancy after abortion

\begin{tabular}{|c|c|c|c|}
\hline Variable & & Odds ratio $(95 \mathrm{Cl})$ & P-Value \\
\hline \multirow[t]{3}{*}{ Age $(\text { years })^{a}$} & $\leq 30$ & $0.718(0.488-1.054)$ & 0.093 \\
\hline & $31-40$ & $0.689(0.506-0.940)$ & $0.019 *$ \\
\hline & $\geq 41$ & 1 & \\
\hline \multirow[t]{3}{*}{ Number of children } & 0 & $0.344(0.135-0.876)$ & $0.025^{\star}$ \\
\hline & 1 & $0.733(0.355-1.516)$ & 0.403 \\
\hline & $\geq 2$ & 1 & \\
\hline \multirow[t]{2}{*}{ obtain free contraceptives in time } & Not in time & $0.609(0.459-0.808)$ & $0.001^{\star}$ \\
\hline & In time & 1 & \\
\hline \multirow[t]{2}{*}{ Use of PAC services } & No & $0.469(0.334-0.659)$ & $0.000^{\star}$ \\
\hline & Yes & 1 & \\
\hline
\end{tabular}

For 900 health care providers, about $60.78 \%$ of them have recommended IUDs to women after abortion. The staff worked in 3-A-grade General Hospitals were 3.220 times significantly more likely to recommend IUDs to women after abortion compared to those who worked in Family Planning Service Center(OR = $3.220,95 \% \mathrm{Cl}: 1.788-5.797)$. The situation was also observed in the staff who worked in Women's and children's Hospital comparing to those who worked in Family Planning Service Center $(O R=2.143$, $95 \% \mathrm{Cl}: 1.274-3.603)$. Health care providers whose workplaces set up the department of family planning(OR $=1.544, \mathrm{Cl}: 1.067-2.233)$ or supplied $\mathrm{PAC}$ services $(\mathrm{OR}=1.987,95 \% \mathrm{Cl}: 1.412-2.795)$ were more likely to recommend IUDs to women after abortion. Comparing to the persons working in the department of maternal and child health, gynaecologists especially working in the department of family planning had higher odds to recommend women to use IUD after abortion(OR $=2.234,95 \% \mathrm{Cl}: 1.303-$ 3.892) (Table 7). Only $29.78 \%$ of them recommend IUDs to unmarried and childless women. The significant predictors described above also influenced health care providers to recommend IUDs after abortion (Talbe 8). 
Table 7

The main factors closely related with the intention to recommend IUDs to women after abortion

\begin{tabular}{|c|c|c|c|}
\hline Variable & & Odds ratio (95 Cl) & $\begin{array}{l}\mathrm{P}- \\
\text { Value }\end{array}$ \\
\hline \multirow[t]{4}{*}{ Workplace. } & 3-A-grade General Hospitals & $\begin{array}{l}3.220(1.788- \\
5.797)\end{array}$ & 0.000 \\
\hline & the basic hospital. & $\begin{array}{l}1.236(0.771- \\
1.981)\end{array}$ & 0.379 \\
\hline & Women's and children's Hospital & $\begin{array}{l}2.143(1.274- \\
3.603)\end{array}$ & 0.004 \\
\hline & Family Planning Service Center & 1 & \\
\hline Setting up & Yes & $\begin{array}{l}1.544(1.067- \\
2.233)\end{array}$ & 0.021 \\
\hline $\begin{array}{l}\text { the department of family } \\
\text { planning }\end{array}$ & No & 1 & \\
\hline \multirow[t]{4}{*}{ Department } & Gynecology department & $\begin{array}{l}1.990(1.262- \\
3.139)\end{array}$ & 0.003 \\
\hline & Obstetrics department & $\begin{array}{l}1.319(0.799- \\
2.810)\end{array}$ & 0.279 \\
\hline & the department of family planning & $\begin{array}{l}2.234(1.303- \\
3.829)\end{array}$ & 0.003 \\
\hline & $\begin{array}{l}\text { Department of maternal and child } \\
\text { health }\end{array}$ & 1 & \\
\hline \multirow[t]{2}{*}{ Supplying PAC services } & Yes & $\begin{array}{l}1.987(1.412- \\
2.795)\end{array}$ & $0.000 *$ \\
\hline & No & 1 & \\
\hline
\end{tabular}


Table 8

The main factors closely related with the intention to recommend IUDs to unmarried and childless women

\begin{tabular}{|c|c|c|c|}
\hline Variable & Odds ratio (95 Cl) & P-Value & \\
\hline \multirow[t]{4}{*}{ Workplace. } & 3-A-grade General Hospitals & $\begin{array}{l}2.485(1.287- \\
4.797)\end{array}$ & 0.007 \\
\hline & the basic hospital. & $\begin{array}{l}2.165(1.165- \\
4.030)\end{array}$ & 0.015 \\
\hline & Women's and children's Hospital & $\begin{array}{l}2.238(1.213- \\
4.128)\end{array}$ & 0.010 \\
\hline & Family Planning Service Center & 1 & \\
\hline Setting up & Yes & $\begin{array}{l}1.545(1.089- \\
2.412)\end{array}$ & 0.05 \\
\hline $\begin{array}{l}\text { the department of family } \\
\text { planning }\end{array}$ & No & 1 & \\
\hline \multirow[t]{4}{*}{ Department } & Gynecology department & $\begin{array}{l}2.167(1.354- \\
3.496)\end{array}$ & 0.001 \\
\hline & Obstetrics department & $\begin{array}{l}0.637(0.488- \\
1.551)\end{array}$ & 0.637 \\
\hline & the department of family planning & $\begin{array}{l}2.737(1.558- \\
4.807)\end{array}$ & 0.000 \\
\hline & $\begin{array}{l}\text { Department of maternal and child } \\
\text { health }\end{array}$ & 1 & \\
\hline \multirow[t]{2}{*}{ Supplying PAC services } & No & $\begin{array}{l}0.419(0.263- \\
0.635)\end{array}$ & $0.000 *$ \\
\hline & Yes & 1 & \\
\hline
\end{tabular}

\section{Discussion}

Guangdong was the most populous province of china. Official data indicated that the induced abortion incidence has maintained more than $50 \%$ in this province(http://www.gdhealth.net.cn/html/tongjishuju/tongjiziliao/). China's a two-child policy has been implemented since 2015. It means that people can have their preferred number of children. IUD was nearly received by all women after the birth of their first child due to the one-child policy[11]. The rate of LARCs use decreased because women could make their own choices. In fact, LARC devices should be first-line contraceptive methods for adolescents[7]. The data showed that the rate of IUD use among married women has reduced in half in Guangdong province since 2015. Problems in contraceptives and influence factors for induced abortion in Guangdong province are still lack of relevant reports. 
The abortion rate in our study was close to that reported in three major cities in china[12]. The percentage of married women and unmarried women experiencing one induced abortion was about $32.78 \%$ and $17.18 \%$ respectively, and $11.72 \%$ of unmarried women and $21.28 \%$ of married women experienced the repeated induced abortion. A review based on nine studies showed that the average value of abortion rates was about $28 \%$, the range of which was from $11-55 \%$ in china $[2,13]$. A recent survey showed that the proportion of repeat induced abortion was high and veried different among 30 provinces in china[14]. The abortion rate in Guangdong province was inside this range. The women in the 40-49 age group had a much higher percentage of induced abortion(38.12\%) and repeated abortion(28.15\%). It was consistent with the findings of other studies due to the experience undergoing the one-child policy during their reproductive age $[12,14,15]$.Although the proportion of induced abortion in women under 20 was lower than that in women over 20 -years of age( $12.5 \%$ vs $30.9 \%)$, the proportion of repeated induced abortion was higher in the the former group( $25 \%$ vs $20.45 \%$ ). In particular, $66.7 \%$ of them were unmarried. It meant that reducing unintended pregnancy in unmarried younger women were grim in Guangdong province.

LARC program has been recommended for adults espercially nulliparous and adolescent patients since 2008. It also was identified as a very effective method for adolescents[16-18]. In our study, the rate of IUD use in participants was $14.5 \% .75 \%$ of women with age less than 20 did not use LARC such as IUD as the common conceptive methods. The rate of IUD use among unmarried women was only $7.74 \%$ in this study. The data were consistent with what were reported in china before[19]. We found that the women with age less than 30 years old or nulliparous women seldom chose IUD as the main contraceptive method due to attempting pregnancy for them. Most of them feared that LARC would cause infertility. Fear of infertility was a major factor for young women's contraceptive decision in the world all along[10, $20,21]$. Out study indicated that the women who had two children often seek LARC. With increase of the education cost and work pressure, many families do not choose to have more children in china. The first consideration for contraception method was efficiency.

Other influencial factors included the provision of PAC services and free contraceptive services. PAC services were first proposed since 1994 and described as the effective method to reduce repeat induced abortion[9]. Providing contraceptive services was one of the important parts. Our questionaire showed that the individual who never used PAC services was significantly less likely to use LARC. It meant that PAC services were very useful to promote LARC use in reproductive age women. In fact, only $14.18 \%$ of persons accepted PAC services in our survey. It was much lower in unmarried women(7.03\%, 18/256). The correlation between the rate of LARC use and provision of PAC services was seldom described before. Other influence factors for PAC services use including living conditions, occupation and monthly income. People have seldom opportunities to obtain PAC services including living in rural areas, with lower income, being self-employed or without jobs. We should pay more attention to those high-risk groups.

The survey in 900 health care providers showed that PAC services not supplied in the staff' workplaces were correlated with their negative attitudes of regarding IUDs use for unmarried and childless women. Out study also indicated that the stuff' age was not the influencing factor. It different from the studies 
before[22]. The possibility was that most health care providers were obstetrics and gynecology physicians and having medicine background. We also found that setting up the department of family planning was important to perform LARC use. The reason may be that PAC services have been one part of works in abortion clinics of some public hospitals since 2010[23]. The doctors who work in the department of family planning mainly provide contraceptive services and induced abortion. Comparing to obstetricians or gynecologists in obstetrics and gynecology, they have relatively enough time to obtain the knowledge of PAC services and performance. The questionnaire revealed that the department of family planning was only set up in $66.22 \%$ of hospitals. This was a common problem that the leadership did not pay attention to this work.

It's worth noting that people who received free contraceptive in time were easier to choose LARC(OR = 1.609, Cl:1.135-2.282). This was the first time to describe the relationship between free contraceptive and LARC use. In china, free contraceptive counselling and reproductive health materials were provided to married women by a government-run Family Planning system in 2004[24]. Free contraceptive use has been identified to be an effective policy in family planning and the reduction of unintended pregnancy[25, 26]. Our study showed that less than half of persons accept contraceptives free of charge and the satisfaction was only $57.1 \%$. We analyzed the influence factors. Variety uniformity, quality and feeling embarrassed were the main reasons. The options for contraceptive pill, intrauterine device and condom free of charge were not plentiful. People who want to obtain free contraceptive services in family planning departments or hospitals will spend spare time. Although they could obtain contraceptives from selfservice terminal at any time, the self-service terminal could not be seen everywhere. Most importantly, they could not obtain consulting service from self-service terminal. Interestingly, the lower income people and the people living in rural areas had more chance to obtain free contraceptives. The people living in rural areas accepted free contraceptives easily because the family planning work was part of the villagelevel leaders' works and it was easily to manage and perform and the leaders pay more attention to those things. Comparing to people with higher income who paid more attention to the quality and types of free contraceptives, low-income groups would consider the price. This result identified that free contraceptive services were apt to some high risk group for PAC services use. Freelance staff or persons without work could also accept free contraceptive services easily. The main reason is that it is difficult to manage and follow up. They could not receive the relevant information from health care providers in time except that they want to know more about those things by themselves. Those people were the concerned objects.

There were some limitations in our study. First, most participants were of Han ancestry and the local residents. Second, we did not study deeply to evaluate how well reproductive aged women master the PAC knowledge and the level of post-abortion care services. Third, we did not distinguish the health care providers based on their education degree. The samples not homogeneously distributing in Guangdong province was also a limitation.

\section{Conclusion}


Our findings first gave a detailed account of the current situation of contraception and induced abortion in Guangdong province. The rate of induced abortion was high especially in unmarried women and younger women. LARC use was not widely accepted espercially in nulliparous women. Some health care providers had negative attitudes regarding IUDs use for nulliparous women or unmarried women. The attentions paid by leaders and setting up the department of family planning were important to improve providers' accurate knowledge of LARC use. Free contraceptive services provided by the government were very useful but there were some limitations. Finding more channels to supply free contraceptive and PAC services for different populations should be performed.

\section{Abbreviations}

LARC: Long-acting Reversible Contraceptives; PAC: Post-abortion Care; OR: Odds Ratio; 95\%Cl: 95\% Confidence Intervals; IUDs: Intra Uterine Device

\section{Declarations}

\section{Acknowledgments}

We are grateful to the staff in our hospital for their contributions to participating in questionnaire and collecting data this study.

\section{Funding}

None.

\section{Availability of data and materials}

The data in our study can be acquired from the corresponding author according to research needs.

\section{Authors' contributions}

QL contributed the central idea, FJ drafted the manuscript, QX and PL were responsible for questionnaire design. LL and QX contributed to revisions, YH and AZ collected data and coordinated the study. All authors read the manuscript and approved the final manuscript.

\section{Ethics approval and consent to participate}

The study was approved by the Ethics Committee of the Guangzhou Women\& Children Medical Center and written informed consent was obtained from all subjects.

\section{Competing interests}

The authors in our study do not have any conflict of interest, financial or otherwise. 
Not applicable.

\section{References}

1. Sedgh G, Bearak J, Singh S, Bankole A, Popinchalk A, Ganatra B, Alkema L. Abortion incidence between 1990 and 2014: global, regional, and subregional levels and trends. Lancet. 2016;388(10041):258-67.

2. National Health and Family Planning Commission of the People's Republic of China China Health Statistics Yearbook, vol. 2018. Beijing: China Union Medical University Press; 2018. p. 227-9.

3. Jatlaoui TC, Eckhaus L, Mandel MG, Nguyen A, Oduyebo T, Petersen E, Whiteman MK. Abortion Surveillance-United States, 2016. Morbidity and mortality weekly report. Surveillance summaries. 2019;68(11):1-41.

4. Wu SC, Qiu HY. Induced abortion in China: problems and interventions. Zhongguo yi xue ke xue yuan xue bao. Acta Academiae Medicinae Sinicae. 2010;32(5):479-82.

5. Lemmers M, Verschoor MA, Hooker AB, Opmeer BC, Limpens J, Huirne JA, Mol BW. Dilatation and curettage increases the risk of subsequent preterm birth: a systematic review and meta-analysis. Hum Reprod. 2016;31(1):34-45.

6. Heikinheimo O, Pohjoranta E, Toffol E, Suhonen S, Partonen T. Induced abortion and mental health. Acta Obstet Gynecol Scand. 2017;96(3):383.

7. Francis JKR, Gold MA. Long-Acting Reversible Contraception for Adolescents: A Review. JAMA pediatrics. 2017;171(7):694-701.

8. ACOG Committee Opinion No. 735: Adolescents and Long-Acting Reversible Contraception: Implants and Intrauterine Devices. Obstetrics gynecology. 2018;131(5):e130-9.

9. Temmerman M. Missed opportunities in women's health: post-abortion care. The Lancet Global health. 2019;7(1):e12-3.

10. Makenzius M, Faxelid E, Gemzell-Danielsson K, Odero TMA, Klingberg-Allvin M, Oguttu M. Contraceptive uptake in post abortion care-Secondary outcomes from a randomised controlled trial, Kisumu, Kenya. PloS one. 2018;13(8):e0201214.

11. Xu JX, Connell C, Chi IC. Immediate postpartum intrauterine device insertion-a report on the Chinese experience. Adv Contracept. 1992;8(4):281-90.

12. Wang X, Wu J, Li Y, Zhou Y, Li Y, Zhao R, Luo M. Changes in the Prevalence of Induced Abortion in the Floating Population in Major Cities of China 2007-2014. Int J Environ Res Public Health. 2019;16(18).

13. Qian X, Tang S, Garner P. Unintended pregnancy and induced abortion among unmarried women in China: a systematic review. BMC Health Serv Res. 2004;4(1):1.

14. Luo H, Wu S, Wang K, Xu J, Tang L, Temmerman M, Zhang WH. Repeat induced abortion in 30 Chinese provinces: A cross-sectional study. Int J Gynaecol Obstet. 2021;1(25). 
15. Sedgh G, Singh S, Henshaw SK, Bankole A. Legal abortion worldwide in 2008: levels and recent trends. Int Perspect Sex Reprod Health. 2011;37(2):84-94.

16. Winner B, Peipert JF, Zhao Q, Buckel C, Madden T, Allsworth JE, Secura GM. Effectiveness of longacting reversible contraception. N Engl J Med. 2012;366(21):1998-2007.

17. Diedrich JT, Klein DA, Peipert JF. Long-acting reversible contraception in adolescents: a systematic review and meta-analysis. Am J Obstet Gynecol. 2017;216(4):364.e361-364.e312.

18. Valeria Bahamondes M. LB. Intrauterine device use is safe among nulligravidas and adolescent girls. Acta Obstet Gynecol Scand. 2021;(Jan 22).

19. Luo Z, Gao L, Anguzu R, Zhao J. Long-acting reversible contraceptive use in the post-abortion period among women seeking abortion in mainland China: intentions and barriers. Reprod Health. 2018;15(1):85.

20. Dassah ET, Odoi AT, Owusu-Asubonteng G. Prevalence and factors predictive of long-acting reversible contraceptive use in a tertiary hospital in urban Ghana. Eur J Contracept Reprod Health Care. 2013;18(4):293-9.

21. Payne JB, Sundstrom B, DeMaria AL. A Qualitative Study of Young Women's Beliefs About Intrauterine Devices: Fear of Infertility. J Midwifery Womens Health. 2016;61(4):482-8.

22. Tang L, Wu S, Li J, Wang K, Xu J, Temmerman M, Zhang WH. Post-abo on family planning counselling practice among abortion service providers in China: a nationwide cross-sectional study. Eur J Contracept Reprod Health Care. 2017;22(1):24-9.

23. The public welfare project 'PAC' had the third anniversary meeting inBeijing. Available from: (http://wwwyiaijijinorgcn/html/xinwenzixun/2014/2014-11/21094141 html) (accessed on 10 Feb 2015).

24. Li J, Temmerman M, Chen Q, Xu J, Hu L, Zhang WH. A review of contraceptive practices among married and unmarried women in China from 1982 to 2010. Eur J Contracept Reprod Health Care. 2013;18(3):148-58.

25. Bakyono R, Tapsoba LDG, Lépine A, Berthé A, Ilboudo PG, Diallo CO, D'Exelle B. Contraceptive use by married women or concubines living in rural areas in Burkina Faso: a qualitative study of free voucher use. Pan Afr Med J. 2020;37:72.

26. Huang Y, Merkatz R, Zhu H, Roberts K, Sitruk-Ware R, Cheng L. The free perinatal/postpartum contraceptive services project for migrant women in Shanghai: effects on the incidence of unintended pregnancy. Contraception. 2014;89(6):521-7.

\section{Figures}




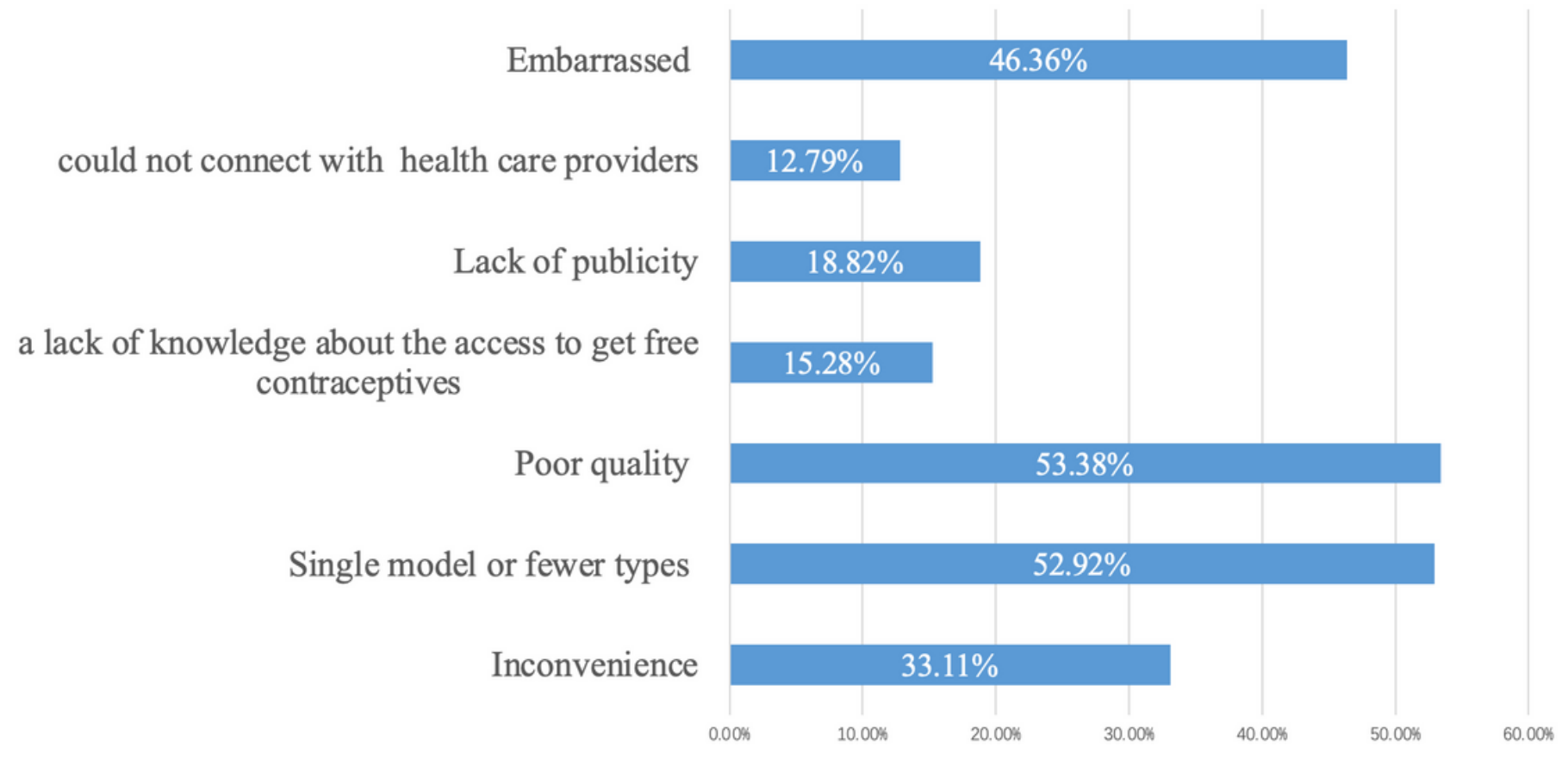

\section{Figure 1}

The influence factors for people refusing free contraceptive services

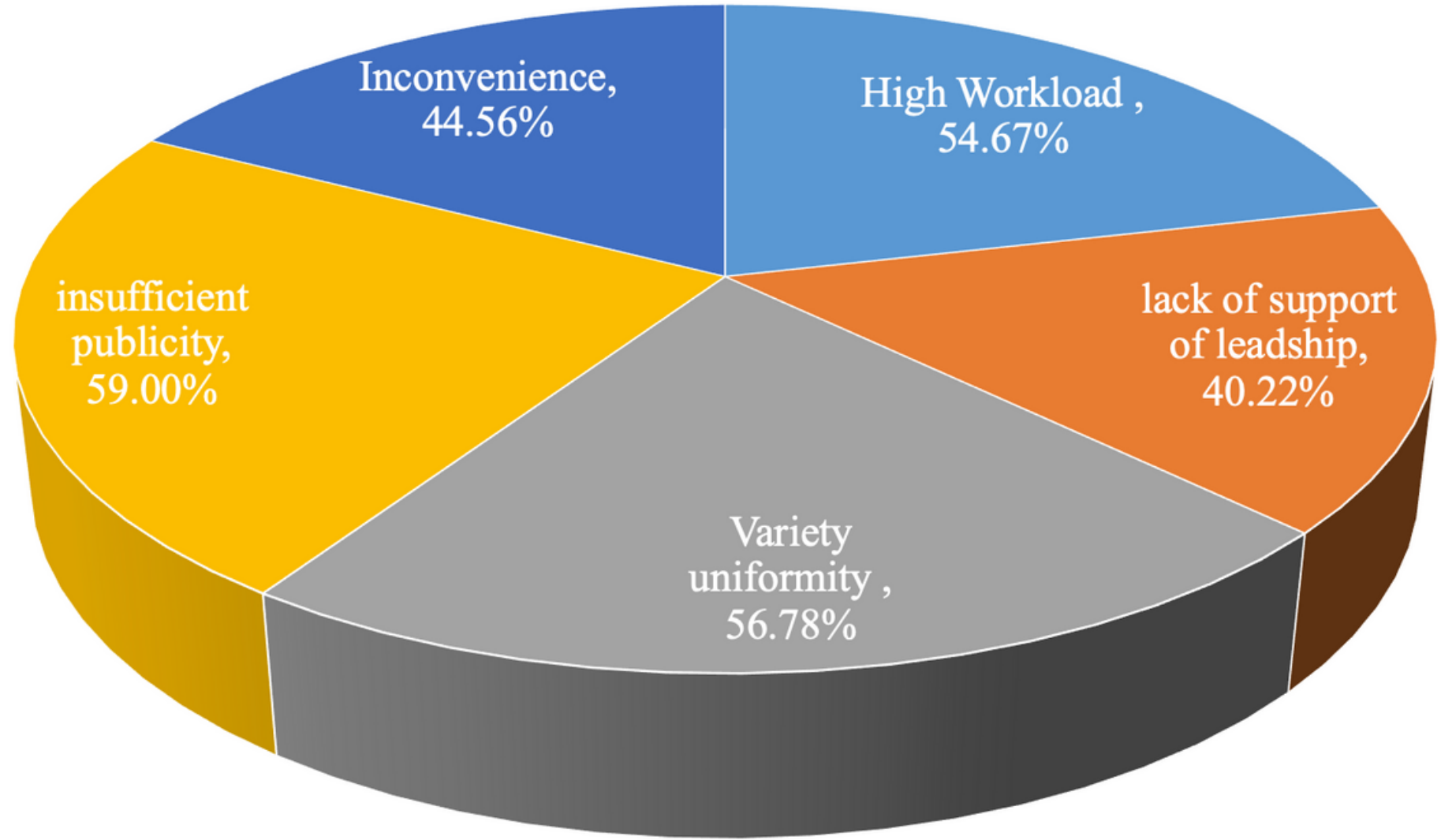

Figure 2 
The problems for health care providers to provide free contraceptive services 